\section{Os caminhos e os (des)caminhos apontados em A Sociedade do Espetáculo para se pensar 0 futebol brasileiro}

\section{RESUMO}

Este texto tem como objetivo apontar algumas perspectivas apresentadas na obra A Sociedade do Espetáculo, de Guy Debord, que nos permitam compreender o futebol brasileiro da atualidade. Para tanto, sugerimos que existem, neste texto, "caminhos e (des)caminhos" a serem considerados. Uma revisão da trajetória do futebol e sua estruturação no país são também contempladas para fins de análise.

\section{ABSTRACT}

This article calls attention to some viewpoints raised in Guy Débord's book Society of the Spetacle which may help us to understand the present state of Brazilian soccer.

\section{PALAVRAS-CHAVE (KEY WORDS) \\ - Futebol brasileiro (Brazilian soccer) \\ - Espetáculo (Spetacle) \\ - Mercadoria (Merchandise)}

"O futebol no Brasil, além de ser um esporte, é também uma máquina de socialização de pessoas, um sistema altamente complexo de comunicação de valores essenciais e um domínio onde se tem garantia da continuidade e da permanência cultural e ideológica enquanto grupo inclusivo. Pois se as formas de governo e a Constituição mudam constantemente, se as universidades, o padrão monetário e os partidos políticos fazem os brasileiros ter muitas dúvidas sobre sua sociedade enquanto nação moderna, aspirante a um lugar ao sol dentro de uma ordem mundial, futebol, carnaval e as relações pessoais dizem que a sociedade brasileira é grande, criativa e generosa, tendo, como acontece com o futebol ali praticado, um glorioso futuro".

\section{O futebol espetáculo: uma introdução}

O futebol é sem dúvida um fenômeno de massas, de mídias, de prazer, de cultura, de popularidade, de economia, de sociabilidade. Chegam até nós diariamente informações sobre vendas milionárias de jogadores, fusões de clubes esportivos com empresas privadas, desvios e propinas para dirigentes envolvidos em transações político-financeiras, novos técnicos e diferentes táticas. Até uma Comissão Parlamentar de Inquérito foi instaurada no Congresso Nacional a fim de desvendar os esquemas de desvios de dinheiro inseridos no meio esportivo. Junto a estas questões podemos incluir os conglomerados da mídia, que negociam os direitos de transmissão dos espetáculos esportivos e as quotas de publicidade. Tudo isso gera pauta, produz e reproduz o espetáculo esportivo da atualidade. A partir deste enfoque, trabalharemos a contribuição de Guy Debord², que considera que a sociedade do espetáculo é isso tudo, cada vez mais estamos aceitando que façam por nós, de modo que, enquanto um executa o outro contempla, o que é, freqüentemente, pouco discutido.

Assistimos diariamente à mídia devassar a vida pessoal dos jogadores, técnicos, enfim, dos "protagonistas" do esporte, em uma simbiose de mudanças 
e transformações, sejam elas quais forem e de onde vêm, porém pouco refletimos sobre as mesmas. A produção cultural, o desenvolvimento do capitalismo tardio e a espetacularização são vertentes que encontramos em $A$ sociedade do espetáculo, cuja primeira edição saiu em 1967, em Paris, para se pensar a própria trajetória do futebol no país.

Este ensaio estrutura-se em três partes. A primeira busca na obra de Guy Debord uma definição da sociedade do espetáculo. A segunda, resgata parte da história do futebol no Brasil a fim de nos aproximarmos do tema, embora sejamos conscientes que, de forma alguma, se esgote aqui as discussões e campos de estudos que possam nortear análises deste tipo. A terceira e última parte, na tentativa de amarrar as anteriores, analisa o futebol espetáculo da atualidade. Assim, as teses defendidas na obra em questão servirão de aportes teóricos para pensamos no que se tornou o futebol contemporâneo.

\section{Apontamentos sobre a sociedade do espetáculo em Guy Debord}

A obra A sociedade do espetáculo ${ }^{3}$ é apontada como uma "aguda" crítica à sociedade que se organiza em torno de constante falsificação da vida comum. $\mathrm{O}$ próprio autor afirmou, em comentários posteriores sobre a sua obra, que se considerava "um raro exemplo contemporâneo de alguém que escreveu sem ser imediatamente desmentido pelos acontecimentos", no sentido de que com o passar dos anos, a contar da primeira edição do livro, em 1967, percebe-se claramente que o "espetáculo aproximouse ainda mais de seu conceito".

Em suas 221 teses, Debord explica que o espetáculo vai muito além dos meios de comunicação de massa, no sentido de que enquadra-o como motor de uma forma de sociedade em que a vida real é pobre e fragmentária, na qual os indivíduos são obrigados a contemplar e a consumir passivamente as imagens de tudo que lhes falta em sua existência real. Na tese 17 , por exemplo, o autor identifica uma de suas características:

"A primeira fase da dominação da economia sobre a vida social acarretou, no modo de definir toda realização humana, uma evidente degradação do ser para o ter. A fase atual, em que a vida social está totalmente tomada pelos resultados acumulados da economia, leva a um deslizamento generalizado do ter para o parecer, do qual todo 'ter' efetivo deve extrair seu prestígio imediato e sua função úl-tima..."(p.18).

Não é nosso objetivo resumir a obra do autor, porém indicar apontamentos presentes em algumas de suas teses que permitam uma melhor compreensão do fenômeno em questão. Debord foi, sobretudo, um humanista preocupado com o cotidiano da cidade, sua degradação e desestrutura, provocada pelo mundo das imagens. Neste sentido, sua análise parte da experiência cotidiana do empobrecimento da vida vivida, da sua fragmentação e da perda de todo aspecto unitário da sociedade. Para o autor, o espetáculo consiste na recomposição destes aspectos separados, através do plano de imagens. E assim, identifica que todo aquele que é carente de vida se reencontra nesse conjunto de representações independentes, que é o espetáculo.

Já nas primeiras teses, Debord identifica que a vida nas sociedades de produção, ditas modernas, se apresenta como uma imensa acumulação de espetáculos, na qual o que antes era vivido diretamente tornou-se uma representação. Todavia, define o espetáculo como resultado e projeto do modo de produção existente: 
"Sob todas as suas formas particulares - informação ou propaganda, publicidade ou consumo direto de divertimentos -, o espetáculo constitui o modelo atual da vida dominante na sociedade. É a afirmação da escolha já feita na produção, e o consumo que decorre desta escolha. A forma e o conteúdo são, de modo idêntico, a justificativa total das condições e dos fins do sistema existente" (p.14).

Guy Debord é incisivo em sua crítica ao capitalismo, poderia se dizer até mesmo crítico radical, pois deixa claro em sua obra que considera não existir nada na cultura e na natureza que não tenha sido transformado ou poluído segundo os meios e os interesses da indústria moderna. Está expresso em seu texto:

"Cada qual é filho de suas obras, e do jeito que a passividade faz a cama, nela se deita. O maior resultado da decomposição catastrófica da sociedade de classes é que, pela primeira vez na história, o velho problema de saber se a maioria dos homens ama de fato a liberdade está superado: agora, eles vão ser obrigados a amá-la" (p.162).

Sua obra, ainda que produzida no final da década de 60 , é atual e em muitos aspectos visionária. Suas teses denunciavam que a mercadoria havia ocupado totalmente a vida social. Ao destacar que não apenas a relação com a mercadoria é visível, defende também que a produção econômica moderna espalha sua ditadura. Refere-se o autor à forma de dominação imperialista, ou seja, acredita que nos lugares menos industrializados reinam as zonas mais avançadas:

"O espetáculo é a outra face do dinheiro: o equivalente geral abstrato de todas as mercadorias. $\mathrm{O}$ dinheiro dominou a sociedade como representação da equivalência geral, isto é, do caráter intercambiável dos bens múltiplos, cujo uso permanecia incomparável. O espetáculo é seu complemento moderno desenvolvido, no qual a totalidade do mundo mercantil aparece em bloco, como uma equivalência geral àquilo que o conjunto da sociedade pode ser e fazer. O espetáculo é dinheiro que apenas se olha, porque nele a totalidade do uso se troca contra a totalidade da representação abstrata. O espetáculo não é apenas o servidor do pseudo-uso, mas já é em si mesmo o pseudo uso da vida" (p.34).

São inúmeras as observações que podem ser feitas a partir das teses defendidas pelo autor, porém, cabe aqui destacar dois elementos específicos presentes na sua obra ${ }^{4}$. O primeiro deles diz respeito do ponto de vista do qual parte Debord para analisar a sociedade. Neste sentido, a tese número quatro sintetiza seu olhar marxista: "O espetáculo não é um conjunto de imagens, mas uma relação social entre pessoas, mediada por imagens" (p.14). Há uma transposição do termo mercadoria para a palavra imagem. Em outra tese, suas observações para se compreender a ideologia marxista são perfeitas:

"O mundo presente e ausente que o espetáculo faz ver é o mundo da mercadoria dominando tudo o que é vivido. E o mundo da mercadoria é assim mostrado como ele é, pois seu movimento é idêntico ao afastamento dos homens entre si e em relação a tudo que produzem" (p. 28).

Seu olhar crítico se explica porque o próprio autor, na tese 207 , defende a necessidade do plágio. Segundo aponta, as idéias melhoram, pois o sentido das palavras entra em jogo. Para ele, o progresso supõe o plágio, de modo que 
considera que ao se aproximar à frase de um autor, serve-se de suas expressões, apagando uma idéia errônea, substituindo pela idéia correta.

Este ponto de vista vem ainda ao encontro dos próprios princípios teóricos do autor, os quais denomina de "teoria crítica do espetáculo". Conforme identifica, esta teoria crítica deve comunicar-se em sua própria linguagem, a da contradição, que deve ser dialética na forma e no conteúdo. Trata-se da crítica da totalidade e crítica histórica, denominada não como uma negação do estilo, mas o estilo da negação.

$\mathrm{O}$ segundo aspecto diz respeito ao espetáculo midiático, isto é, a estratégia explícita de substituição utilizada pelos meios de comunicação e pela mídia como um todo, considerando a sensação de conforto que este espetáculo produz. Sobre este aspecto, o autor irá considerar, em seus comentários posteriores à obra propriamente dita, que a sociedade modernizada até o estágio do espetacular integrado se caracteriza pela combinação de cinco aspectos principais 5 : a incessante renovação tecnológica, o segredo generalizado, a mentira sem contestação e o presente perpétuo.

Ao caracterizar cada um destes aspectos, considera que o movimento de inovação tecnológica é constitutivo da sociedade capitalista, chamada de industrial ou pós-industrial, que, desde o período pós-guerra, recebeu o impulso necessário, reforçando a autoridade espetacular, entregue ao corpo de especialistas e de seus cálculos; a fusão econômico-estatal é a tendência mais manifesta no século $X X$ e o motor do desenvolvimento recente.

Os três últimos aspectos, segundo o autor, são efeitos diretos da dominação espetacular. O segredo generalizado mantém-se por trás do espetáculo, como complemento decisivo daquilo que se mostra. $O$ fato de não existir contestação conferiu à mentira uma nova qualidade, ao mesmo tempo que a verdade ficou reduzida a uma hipótese que nunca será demonstrada, consumando o desaparecimento da opinião pública. Por fim, a construção do presente, em que a própria moda, do vestuário aos cantores, se imobilizou. Explica o autor, neste sentido, que se quer esquecer o passado e dar a impressão de já não se acreditar no futuro. Esta permanente invocação do presente é conseguida pela circulação incessante da informação, assim identificada:

“(...) a cada instante retorna uma lista bem sucinta das mesmas tolices, anunciadas com entusiasmo como novidades importantes, referentes ao que de fato muda. Tais tolices dizem respeito sobretudo à condenação que este mundo parece ter pronunciado contra sua existência, às etapas de sua autodestruição programada" (p.176).

Veremos posteriormente como estas características podem ser aplicadas à temática proposta neste ensaio. No momento, cabe ressaltar, conforme o autor, que o poder do espetáculo, tão unitário, costuma ficar indignado quando vê constituir-se sob seu reino uma "política-espetáculo, uma justiçaespetáculo, uma medicina-espetáculo, ou outros tantos surpreendentes excessos midiáticos". Paradoxalmente, os "donos" da sociedade declaram-se mal servidos por seus empregados midiáticos e ainda censuram os espectadores pela tendência a entregar-se sem reservas aos prazeres da mídia. Por trás de uma infinidade de "pseudodivergências" midiáticas, aponta Debord, fica dissimulado o oposto, que seria o resultado de uma convergência espetacular buscada com muita tenacidade. E assim, a lógica da mercadoria predomina sobre as diversas ambições concorrenciais, incluindo-se a rigorosa lógica do espetáculo, que comanda as "exuberantes e as diversas extravagâncias da mídia".

Porém, salienta o autor, a mudança de maior importância reside na própria 
continuidade do espetáculo, que não decorre simplesmente do aperfeiçoamento e da instrumentalização midiática, mas sobretudo do fato de a dominação espetacular ter podido educar uma geração submissa às suas leis.

\section{Preliminares: a trajetória do futebol brasileiro}

Antes de se entrar no espetáculo futebolístico propriamente dito, faz-se necessário, ainda que breve, algumas observações sobre a trajetória inicial do futebol no Brasil 6 , salientando elementos considerados relevantes no seu desenvolvimento.

O primeiro contato do Brasil com o futebol foi em 1894, através de Charles W. Miller, brasileiro filho de imigrantes ingleses, que passou uma temporada de estudos em Londres e, ao retornar ao país, trouxe, além de uma bola, a técnica do jogo com o intuito de difundir a prática do futebol entre os residentes ingleses em São Paulo (Caldas, 2001).

Logo em seguida, os ingleses, dos mais altos cargos da Companhia de Gás, do Banco de Londres e da São Paulo Railway, ingressaram na prática do futebol. E assim, o São Paulo Athletic Club, fundado inicialmente para a prática de cricket, aderiu em seu espaço lúdico, em 1887, a esta nova modalidade esportiva. O ano de 1899 marca a realização do primeiro "grande" jogo em São Paulo, com a presença de cerca de 60 torcedores.

A trajetória inicial do futebol possui caráter elitista, dificilmente isto seria diferente, pois os seus precursores ingleses faziam parte da alta sociedade. Dos brasileiros somente os ricos tinham acesso à pratica deste esporte. Os colégios "grãfinos" do Rio de Janeiro e de São Paulo adotaram, a partir da primeira década do século passado, o futebol como prática recreacionista para seus alunos. Surgindo daí os bons jogadores, que passaram a integrar os clubes das tradicionais famílias, como o Clube Athlético Payssandu (RJ), - Germânia (atual Pinheiros), o São Paulo Athletic, entre outros ${ }^{7}$. Conforme o pesquisador:

"Em 1903, os aristocratas do café, da Associação Athlética Ponte Preta, formam o que seria o primeiro time de futebol organizado do Brasil, segundo registros oficiais da Confederação Brasileira de Futebol. Surgem também, na década de 10, o The Bangu Athletic Club, o Carioca, o Andaraí, o Mangueira, o Fluminense, o Vila Isabel e o Sport Club Corinthians Paulista" (p.100).

Destaca-se, então, o The Bangu Athletic Club, que apesar da "nobreza" do nome, sempre teve tendências proletárias. Salienta o autor que, ainda que tenha sido fundado por funcionários de altos cargos da Cia. Progresso, localizada na periferia e em meio a um bairro proletário, esta empresa estimulou a prática do futebol como atividade de lazer entre seus executivos. A fim de solucionar o problema de formação de times, já que o número de funcionários não chegava a tanto, optou-se pela alternativa de aceitar operários para completar as duas quadras. O critério de escolha de jogadores obedecia algumas exigências da empresa, conforme observou Caldas: o desempenho profissional, o tempo de serviço e o comportamento pessoal. Fazendo surgir assim, por questões circunstanciais, o primeiro time de futebol no Brasil não elitizado.

O privilégio de ser escolhido criou uma nova categoria profissional, identificada pelo autor como "operáriojogador", que veio a formar a elite operária do futebol, com direito a regalias como, por exemplo, fazer um trabalho mais leve para concentrar suas energias no futebol e em dia de jogo deixar o trabalho mais cedo. Contudo, tornaram-se estes jogadores, aos poucos, protegidos pela diretoria e quase sempre promovidos. Em pouco tempo, o 
time formado por jogadores tornou-se mais conhecido do que a própria Cia. Progresso, que a partir daí passou a ser um excelente veículo de publicidade da empresa, pois criavam uma imagem simpática por onde passavam.

O contexto brasileiro da época sinalizava traços não muito estáveis. A industrialização durante a República Velha praticamente inexistiu, mesmo com a abolição da escravatura, que dificultava o desenvolvimento do capitalismo no país, a produção industrial pouco mudou no período. Vivia-se da monocultura cafeeira e de uma economia inexpressiva, pois o processo de industrialização só foi surgir de forma sistemática na década de 30 . Aponta Caldas em seu estudo sobre a história do futebol (op.cit.):

"Neste aspecto, a Cia. Progresso tem caráter duplamente pioneiro. Foi uma das primeiras indústrias de manufatura têxtil do país, quando ainda não se pensava numa política industrial. Além disso, transformou a imagem da empresa numa instituição vitoriosa, graças às conquistas do Bangu nos campos de futebol. A população associava os tecidos Bangu (era esse o nome da produção têxtil da Cia. Progresso) ao vitorioso time de futebol" (p.102).

Ao mesmo tempo em que os executivos ingleses começaram a ceder seus lugares aos operários, o Bangu também era o único time que dava lugar aos negros, ainda que com restrições.

Com a contínua popularização do futebol, a partir da segunda metade dos anos 20 surgiram alguns impasses que envolviam questões políticas e sociais. Caldas relaciona alguns desses: havia clubes que relutavam em aceitar a crescente popularização do futebol; considerando que tanto os jogadores como o público pertenciam às classes mais abastadas, não haveria motivos para profissionalizar o esporte, já que poderiam se manter com a venda de ingressos; os clubes de subúrbio, não elitizados, começavam a "roubar" o espetáculo apresentando bons jogadores. Contudo, por mais que tentassem impedir que o futebol rumasse para o profissionalismo, o máximo que conseguiram foi adiá-lo. Entre outros fatores históricos, o autor salienta que a antiga CBD, fundada em 1916, "fazia o jogo das agremiações elitistas", pois os presidentes de clubes eram, na sua maioria, políticos, e constantemente viam-se em situação difícil: se apoiassem a profissionalização perderiam o apoio da elite, por outro lado, caso incentivassem tornariam sua imagem mais simpática aos eleitores. Tornando-se, assim, necessário o surgimento da figura do "cartola", que, já naquela época, trabalhava muito mais pelo jogo de interesses pessoais do que para o futebol em si.

A imprensa era favorável ao profissionalismo e contra o que chamavam "profissionalismo marrom", ou seja, oficialmente o futebol ainda era amador, só que já havia pagamentos para jogadores (op.cit.):

"Isso caracterizava um tipo de futebol semiprofissional que só interessava aos clubes. Enquanto as arrecadações nos estádios aumentavam e enriqueciam ainda mais as agremiações, os jogadores permaneciam na mesma situação de explorados e sem nenhum direito" (p.103).

O declínio do elitismo foi presenciado a partir dos anos 30, com a ascensão do profissionalismo, embora não tenha eliminado preconceitos de classe e cor (Caldas, 1990). A situação começa a se modificar, de fato, no momento em que inicia o êxodo de jogadores brasileiros para a Europa e alguns países sul-americanos, cujos motivos eram o falso amadorismo e a exploração do trabalho (ibid.). 
No entanto, no plano político, o país assiste a uma grave crise. A Revolução de 30 obriga o presidente Washington Luís a renunciar e Getúlio Vargas toma o poder, encerrando o período da República Velha. Ao assumir a presidência, Vargas apresenta seu projeto de governo, destacando medidas imediatas a serem tomadas através do "Programa de Reconstrução Nacional". Conforme considera o autor, estas medidas foram benéficas para 0 atleta e o futebol brasileiro, pois havia um item no projeto de governo destinado a instituir o Ministério do Trabalho, para superintender a questão social e o amparo ao trabalhador rural e urbano. A legislação trabalhista de Vargas, implantada entre 1930 e 1936, regulamentou profissões até então nunca cogitadas no país, e o futebol estava entre elas:

“(...) em 23 de janeiro de 1933, estaria definitivamente implantado o futebol profissional no Brasil, em que se pese o comportamento amador de dirigentes até hoje. (...) reitera-se com a profissionalização nos anos 30 o caráter de união e de identidade nacional através do futebol que, a essa altura, já estava definitivamente incorporado à cultura lúdica brasileira" (p.104).

A partir de 1930 o futebol tornou-se espetáculo, pois cerca de cinqüenta mil pessoas já compareciam aos clássicos da época. Ao mesmo tempo em que aparecia o público nos estádios, crescia o público para os jornais, o rádio e, em menor escala, para o livro (Santos, 1981). O autor observa, ainda, que o rádio, importante veículo deste tempo, ligava as duas atividades de massa: o futebol e o samba, enquanto a legislação trabalhista, ao mesmo tempo que protegia o trabalhador, organizava o mercado de trabalho para facilitar o desenvolvimento do capitalismo.

"Sem o rádio, não se pode conceber a popularização do futebol, a idolatria que ele gerou - por Domingos, por Hércules, por Valdemar de Brito, mas sobretudo por Leônidas. Estes, e mais artistas de rádio, como Noel Rosa e Carmem Miranda, foram os primeiros ídolos de nosso país, reverenciados onde quer que suas ondas chegassem. Ora, o rádio, o cinema, o automóvel, o avião difundiram-se aqui graças à Revolução de Trinta; foram, por assim dizer, o seu fator tecnológico" (p.54).

As conquistas das Copas de 58 e 62 foram então frutos de uma época, com o fim do populismo o futebol brasileiro toma outro rumo. Já no governo JK (1956-60) chega-se ao final de um ciclo histórico. Até então, perseguíamos o desenvolvimento de um capitalismo nacional, o Estado era o centro das decisões políticas e econômicas mais importantes, pois formulava, orientava e executava pontos de um programa de expansão. Com JK iniciou-se a abertura da economia ao exterior, mediante estímulos às exportações e a ampla importação de capital, sob forma de investimentos ou empréstimos. Houve ainda a expansão do crédito ao consumidor e o estímulo à poupança interna, entre outros fatores, que apontavam para um novo ciclo histórico, construído por Juscelino e ampliado pelo governo Médici (1969-72). Segundo o autor (op.cit.):

\section{“(...) no lugar da política de massas anterior, favorável à exploração do talento brasileiro, este modelo forçou à exploração de uma política antipopu-lar. Para o nosso povo foi uma camisa-de-força" (p.81).}

Com a militarização do país, o futebol deixou de ser alegre e agressivo para ser triste e defensivo. Os militares que assumiram os clubes e a organização do futebol acreditavam mais no técnico e no esquema de jogo do que no jogador, que 
pouco a pouco foi perdendo a confiança no seu futebol-arte, aprendido na rua, de geração em geração.

De certa forma, estes mesmos fatores abriram caminho para um novo tipo de futebol, que dos anos 80 para cá vem sendo gestado pelo avanço do marketing esportivo. Porém, na década de 90, assistiu-se à efetivação de tal modelo, considerado como uma saída inexorável para a situação deficitária dos torneios, quando houve uma corrida para buscar novas fontes de receitas para aumentar a competitividade dos times ${ }^{8}$ (Proni, 1999).

Através desta breve revisão histórica observamos que o futebol, desde sua implantação no Brasil, se organizou não somente de acordo com o contexto social e cultural vigente, mas também econômico.

\section{O jogo: futebol-mercadoria}

A partir das duas perspectivas já relacionadas neste ensaio, uma que define a sociedade do espetáculo em que vivemos atualmente, e outra que trata basicamente de um ponto de vista histórico, busca-se, neste sentido, identificar os caminhos e os (des)caminhos para se pensar o futebol no país.

As tendências atuais de reconfiguração do futebol brasileiro foram produzidas pela alteração na legislação esportiva e pela expansão dos mercados associados à comercialização do espetáculo e dos símbolos futebolísticos. Proni (op.cit.), ao refletir sobre o futebolempresa no Brasil, identifica, pelo menos, seis processos diferentes. Em primeiro lugar, atenta para quem dirige o futebol no país: a CBF. De 1996 para cá, vem aproveitando da imagem construída pela tradição futebolística do país firmando contratos com empresas patrocinadoras, a exemplo da Nike e da Coca-cola; a primeira, se dispôs a pagar US\$ 170 milhões, mais as despesas com transporte e hospedagem por dez anos de exclusividade no fornecimento do material esportivo e o direito de promover partidas amistosas; a segunda, paga mais de US\$ 2 milhões por ano. Desde então, a CBF vem sendo gerida, na prática, como uma empresa, porém, não cabe aqui avaliar, senão apontar que ainda que tenha se tornado superavitária, vem apresentando um balanço deficitário. Em segundo lugar, as empresas de comunicação vêm aumentando seus investimentos no futebol. Houve, nos últimos anos, uma valorização expressiva nas cotas de publicidade, acirrando a concorrência para a obtenção dos direitos de transmissão. A Rede Globo detém os direitos dos principais campeonatos (Brasileiro, Paulista, Carioca, Copa do Brasil). Em resposta a esta política, a Bandeirantes foi obrigada a negociar o controle do seu departamento esportivo. Devido aos altos custos com a produção da programação, assumiu o comando do esporte na emissora a maior empresa de marketing esportivo do país, a Traffic. Em terceiro lugar, Proni salienta o desenvolvimento do marketing esportivo, que a partir do sucesso da parceria "Palmeiras-Parmalat" vem despertando o interesse de muitas empresas em explorar a projeção que o futebol pode conferir a uma marca. Para se ter uma idéia, no início da década de 90 os salários de uma grande equipe não ultrapassavam US\$ 40 mil mensais, atualmente, destaca o autor, algumas chegam a gastar US\$ 800 mil mensais; em salários, ao passo que outras são bem modestas, pois as equipes têm portes distintos, dependendo do tamanho da torcida, da tradição e da região onde se inserem. Em quarto lugar, está a entrada de instituições financeiras no mundo do futebol. O retorno para o banco pode ser avaliado pela sua exposição na mídia, pela valorização de sua imagem e patrimônio, sendo que os exemplos são o Banco Excel-Econômico com o Corinthians e o Vitória da Bahia, o Vasco da Gama com o National/Liberal, e a mais recente parceria gaúcha do Banco do Estado do Rio Grande 
do Sul com o Grêmio e o Internacional. Em quinto lugar, observa o autor, que pressionados pela Lei Pelé, os clubes vêm buscando caminhos variados para adotar a gestão empresarial, através de parcerias com o setor privado. Em sexto e último lugar, destacam-se mudanças na forma de como os torneios vêm sendo organizados e o papel das federações estaduais. Há um debate inacabado sobre a reformulação do calendário futebolístico e o destino dos campeonatos.

O autor conclui suas observação afirmando que:

“(..) por intermédio da ação de distintos agentes, a lógica do mercado tem dado o tom da modernização em curso no futebol brasileiro. Contudo, como não foram definidos limites ou parâmetros a esse processo de metamorfose, as rupturas se tornam mais profundas e imprevisíveis. As contradições geradas por essas mudanças sem freios colocam em xeque a continuidade das tradições criadas ao longo do século" (p.51).

Há ainda outro aspecto que deve ser considerado, haja vista as contradições que podem ocorrer na relação entre o clube e sua torcida. O futebol-empresa, conforme vimos, surgiu na década de 60 , quando os torcedores passaram a ser tratados como clientes, isto é, consumidores do espetáculo, de artigos esportivos e serviços oferecidos pelo clube, além dos produtos licenciados. Não apenas com o futebol, assistiu-se, neste período, à efetivação de uma indústria cultural no país.

No entanto, a expansão foi tanta, que se identifica atualmente que o propósito de investimentos no futebol tem duas vias: o controle de transmissões e a gestão dos clubes, uma vez que se ganha com a venda de assinaturas de TV (pay-perview), por um lado, e com a valorização dos patrocínios e merchandising, de outro. Segundo Proni, há um exemplo a ser considerado:

“(...) é a investida do grupo HMTF, que, além de estar adquirindo o controle sobre o futebol profissional de alguns clubes de expressão, também entrou no mercado de tevê por assinatura (é sócio da TV Cidade) e se associou à Traffic (empresa que detém os direitos de transmissão de vários torneios e o controle do departamento de esporte da Rede Bandeirantes de Televisão). Entretanto, quem domina o mercado é a Rede Globo (...)" (p.55).

Neste sentido, as objeções quanto a este movimento residem num eventual monopólio das transmissões, na possibilidade de poucos grupos econômicos deterem o controle dos principais clubes do país e na propensão dos canais de televisão virem a beneficiar algumas equipes em detrimento das demais. Questiona-se, ainda, a capacidade que terão os clubes de médio porte para atrair investidores privados e competirem com os grandes, num cenário em que espaços tendem a ser ocupados por aqueles que tiverem a mídia a seu favor (op.cit.).

Os caminhos e os (des)caminhos do futebol brasileiro: algumas considerações

Iniciamos este ensaio salientando que, no nosso ponto de vista, havia caminhos e (des)caminhos na obra de Guy Debord para se pensar o futebol brasileiro da atualidade.

Os apontamentos teóricos extraídos da referida obra para a elaboração deste trabalho explicariam por si só, se não considerássemos importante um embasamento histórico para compreendermos o fenômeno em questão. Portanto, acreditamos que a contextualização histórica em termos da trajetória de desenvolvimento do futebol, desde sempre, permite uma aproximação maior a este universo de estudo. Definir o que se entende por sociedade do 
espetáculo não basta para nosso objetivo último, ainda que se considere esta obra, escrita em 1967, quando a televisão ensaiava uma estruturação, a tecnologia ainda não havia permeado amplamente nosso cotidiano e a indústria cultural se estruturava como entretenimento em meio à realidade e a ficção.

Debord anuncia a fase do "ter para o parecer", da "representação", do "espetáculo", do "dinheiro que apenas se olha", como modelo dominante de vida na sociedade atual.

Assim, verifica-se que a trajetória do futebol em nosso país é igualmente permeada pelo desenvolvimento do capitalismo, do modo que qualifica a gestação e a passagem para a fase de espetacularização, propagada através do rádio, estruturada nos anos 60 , porém amplamente difundida nos anos 90 .

Nos dias de hoje pouco, ou quase nada, se assiste do futebol-arte durante anos aqui praticado, não se vê mais o talento de um jogador, mas uma indústria de (super)jogadores. A prática deste esporte já não faz mais história, no sentido de que o jogo é o espetáculo, com início, meio e fim e ponto final, numa busca ao eterno presente, como já apontara Debord ao caracterizar a sociedade moderna. A inovação tecnológica foi também fator último na constituição do espetáculo futebolístico da atualidade, pois transmissões via satélite, câmeras, enfim, todo o aparato tecnológico disponível, colocam-nos na condição de contempladores. Vimos que a fusão econômica estatal fizeram parte de sua história. Há também um segredo generalizado, também transformado em índices de audiência, como o caso do Ronaldinho na final da última Copa do Mundo, ou até mesmo da CPI que (des)enrola no Congresso Nacional.

Por outro lado, há uma relação de identidade e prazer que não pode ser desconsiderada. Em meio a toda esta "des(organização)" do futebol brasileiro está o torcedor, que em nome de uma paixão tornou-se consumidor.

Para o brasileiro, conforme DaMatta (1986), a palavra futebol nunca surge sozinha, é sempre precedida pelo qualificativo jogo. O futebol praticado no país deve ser visto não só como um esporte, mas também como um jogo de todo um outro conjunto de valores e relações sociais. A música, o relacionamento com os santos e espíritos, a hospitalidade, a amizade, a comensalidade e, naturalmente, o carnaval e o futebol permitem ao brasileiro entrar em contato com o seu mundo social: "nestes domínios, as regras não mudam e são aceitas indistintamente por todos", aponta o autor.

Não há resposta para os rumos que o futebol brasileiro tomará, só especulações. Entretanto, uma coisa é certa: ainda que tenha se tornado um produto cultural (mercadoria), existe uma relação cultural que as regras do mercado pensam dominar, mas que ainda não dão conta, efetivamente, deste universo .

\section{Notas}

1 Trecho do texto Futebol: ópio do povo ou drama de justiça social? de Roberto DaMatta, publicado em Explorações de Sociologia Interpretativa, em 1986, Editora Rocco.

2 Anselm Jappe, biografo de Debord (1931-1994), aponta que ele não é apenas um dos poucos autores de inspiração marxista que hoje podem dar uma contribuição importante para a análise do capitalismo globalizado e pós-moderno. Sua vida singular, sem compromissos e conforme às suas teorias, confirma que viveu às margens da sociedade: sem trabalho reconhecido, sem contato com as instituições ou mesmo ter freqüentado a universidade, conseguiu ser ouvido e levou a diante a sua batalha contra a sociedade do espetáculo. Foi um dos fundadores da Internacional Situacionista, organização que existiu entre 1957 e 1972, fruto da decomposição do surrealismo parisiense e outras experiências artísticas. Entre outros temas, os situacionistas criticavam a nova arquitetura, 0 vazio e o tédio do pós-guerra. Suas poucas intervenções miradas e idéias subversivas tornaram-se em 1968 e, posteriormente, um fator histórico de primeira ordem. FSP, Mais!, 17 de agosto de 1997, p.4-5. 
3 Cf. DEBORD, Guy. A sociedade do espetáculo. Comentários sobre a sociedade do espetáculo. Rio de Janeiro: Contraponto, 1997.

4 No plano teórico, Debord (p.172) destaca que, em 1967, distinguia o poder espetacular em duas formas rivais e sucessivas: a concentrada e a difusa (ver definições nas teses 64 e 65); no entanto, em seus comentários posteriores, 0 autor agrega uma nova forma, como uma combinação das anteriores, a do espetacular integrado, por considerar que "(...) hoje, nada lhe escapa. 0 espetáculo confundiu-se com toda a realidade, ao irradiála".

5 Estas idéias do autor estão expressas no $\mathrm{V}$ item de seus "Comentários sobre a sociedade do espetáculo", que constituem a última parte da edição brasileira da referida obra. Cf. Referências bibliográficas deste trabalho.

6 É extensa a bibliografia que contempla o futebol brasileiro, privilegiamos neste trabalho dois autores que são referências nesta temática: Waldenyr Caldas e Joel $R$. dos Santos. Esta escolha deve-se ao fato de não apenas contemplarem a história, mas porque a inserem num contexto amplo de cultura, economia, política e sociedade.

7 Abre-se parêntese para destacar o pioneirismo gaúcho. A trajetória do futebol no Rio Grande do Sul inicia em 19 de julho de 1900 com a fundação do Sport Club Rio Grande, primeiro e mais antigo time de futebol brasileiro em atividade. Naquela época, o Brasil com onze anos de República, mantinha relações comerciais intensas com as três potências mundiais de então: Inglaterra, França e Alemanha. 0 município de Rio Grande, no início do século XX, já possuía um efervescente porto de entrada e saída de produtos. Contudo, a classe alta da sociedade local, que ostentava hábitos cosmopolitas, correu atrás da nova modalidade esportiva que era 0 encanto da juventude européia (Denardin, s/d). No entanto, foram clubes como o Grêmio Foot-ball Porto Alegrense e o Sport Clube Internacional, fundados em Porto Alegre, respectivamente, 1903 e 1909, que ajudaram a consagrar o futebol não apenas nacionalmente, mas fora do país.

8 Por outro lado, as mudanças na legislação esportiva visando modernizar o futebol brasileiro, primeiro com a Lei Zico e depois com a Lei Pelé, aceleraram a implantação de uma gestão empresarial.

\section{Referências}

CALDAS, Waldenyr. 0 pontapé inicial. Memória do futebol brasileiro. São Paulo: Ibrasa, 1990.

Temas da cultura de massa: música, futebol e consumo. São Paulo: Arte \& Ciência, Villipress, 2001.

DEBORD, Guy. A sociedade do espetáculo: Comentários sobre a sociedade do espetáculo. Rio de Janeiro: Contraponto, 1997.

DENARDIN, Pedro Ernesto \& DIESTMANN, Cláudio. Um século de futebol: Do Sport Club Rio Grande ao Clube dos Treze. Porto Alegre: Gráfica Aplub, s/d.

PRONI, Marcelo Weishaupt. "Reflexões sobre o futebol empresa no Brasil". In: COSTA, Márcia R.; FLORENZANO, José P.; QUINTILHO, Elizabeth; D'ALLEVEDO, Silvia C.; SANTOS, Marco Antônio S. (orgs.). Futebol: espetáculo do século. Núcleo de Estudos do Cotidiano e de Cultura Urbana PEPGCS/PUC-SP. São Paulo: Musa Editora, 1999, p.41-60.

SANTOS, Joel Rufino. História política do futebol brasileiro. São Paulo: Brasiliense, 1981.

"Código, padrão e respeito". In: COSTA, Márcia R.; FLORENZANO, José P.; QUINTILHO, Elizabeth; D'ALLEVEDO, Silvia C.; SANTOS, Marco Antônio S. (orgs.). Futebol: espetáculo do século. Núcleo de Estudos do Cotidiano e de Cultura Urbana PEPGCS/PUC-SP. São Paulo: Musa Editora, 1999, p. 103-111. 